\title{
Does Internet-based guided-self-help for depression cause harm? An individual participant data meta-analysis on deterioration rates and its moderators in randomized controlled trials
}

\author{
D. D. Ebert ${ }^{1 *}$, L. Donkin ${ }^{2,3}$, G. Andersson ${ }^{4,5}$, G. Andrews ${ }^{6}$, T. Berger ${ }^{7}$, P. Carlbring ${ }^{8}$, A. Rozenthal ${ }^{8}$, \\ I. Choi ${ }^{9}$, J. A. C. Laferton $^{10}$, R. Johansson ${ }^{4,5}$, A. Kleiboer ${ }^{3}$, A. Lange ${ }^{11}$, D. Lehr ${ }^{12}$, J. A. Reins ${ }^{12}$, \\ B. Funk ${ }^{12}$, J. Newby ${ }^{13}$, S. Perini ${ }^{14}$, H. Riper ${ }^{3}$, J. Ruwaard ${ }^{3}$, L. Sheeber ${ }^{15}$, F. J. Snoek ${ }^{16,17}$, N. Titov ${ }^{18}$, \\ B. Ünlü Ince ${ }^{3}$, K. van Bastelaar ${ }^{16}$, K. Vernmark ${ }^{4,19}$, A. van Straten ${ }^{3}$, L. Warmerdam ${ }^{3}$, N. Salsman ${ }^{20}$ \\ and P. Cuijpers ${ }^{3}$
}

\begin{abstract}
${ }^{1}$ Friedrich Alexander University Erlangen-Nuremberg, Erlangen, Germany; ${ }^{2}$ The Brain and Mind Research Institute, University of Sydney, NSW, Australia; ${ }^{3}$ Department of Clinical, Neuro and Developmental Psychology, VU University Amsterdam, the Netherlands; ${ }^{4}$ Department of Behavioural Sciences and Learning, Linköping University, Linköping, Sweden; ${ }^{5}$ Department of Clinical Neuroscience, Karolinska Institute, Stockholm, Sweden; ${ }^{6}$ Clinical Research Unit for Anxiety and Depression, School of Psychiatry, University of New South Wales at St Vincent's Hospital, Darlinghurst, NSW, Australia; ${ }^{7}$ Department of Clinical Psychology and Psychotherapy, University of Bern, Bern, Switzerland; ${ }^{8}$ Department of Psychology, Stockholm University, Sweden; ${ }^{9}$ Brain and Mind Centre, University of Sydney, Sydney, Australia; ${ }^{10}$ Psychologische Hochschule Berlin; ${ }^{11}$ Department of Clinical Psychology, University of Amsterdam, Amsterdam, The Netherlands; ${ }^{12}$ Leuphana University Lüneburg, Germany;

${ }^{13}$ Clinical Research Unit for Anxiety and Depression, School of Psychiatry, University of New South Wales at St Vincent's Hospital, Darlinghurst, NSW, Australia; ${ }^{14}$ Centre for Emotional Health, Macquarie University, Australia; ${ }^{15}$ Oregon Research Institute, Eugene, Oregon, USA;

${ }^{16}$ Department of Medical Psychology, VU University Medical Center Amsterdam, The Netherlands; ${ }^{17}$ Academic Medical Center/University of Amsterdam, The Netherlands; ${ }^{18}$ eCentreClinic and MindSpot Clinic, Department of Psychology, Macquarie University, Australia;

${ }^{19}$ Psykologpartners, Private Practice, Linköping, Sweden; ${ }^{20}$ School of Psychology, Xavier University, Cincinnati, USA
\end{abstract}

Background. Almost nothing is known about the potential negative effects of Internet-based psychological treatments for depression. This study aims at investigating deterioration and its moderators within randomized trials on Internet-based guided self-help for adult depression, using an individual patient data meta-analyses (IPDMA) approach.

Method. Studies were identified through systematic searches (PubMed, PsycINFO, EMBASE, Cochrane Library). Deterioration in participants was defined as a significant symptom increase according to the reliable change index (i.e. 7.68 points in the CES-D; 7.63 points in the BDI). Two-step IPDMA procedures, with a random-effects model were used to pool data.

Results. A total of 18 studies (21 comparisons, 2079 participants) contributed data to the analysis. The risk for a reliable deterioration from baseline to post-treatment was significantly lower in the intervention $v$. control conditions (3.36 $v$. 7.60; relative risk $0.47,95 \%$ confidence interval $0.29-0.75$ ). Education moderated effects on deterioration, with patients with low education displaying a higher risk for deterioration than patients with higher education. Deterioration rates for patients with low education did not differ statistically significantly between intervention and control groups. The benefit-risk ratio for patients with low education indicated that 9.38 patients achieve a treatment response for each patient experiencing a symptom deterioration.

Conclusions. Internet-based guided self-help is associated with a mean reduced risk for a symptom deterioration compared to controls. Treatment and symptom progress of patients with low education should be closely monitored, as some patients might face an increased risk for symptom deterioration. Future studies should examine predictors of deterioration in patients with low education.

Received 23 July 2015; Revised 5 June 2016; Accepted 15 June 2016

Key words: Adverse events, depression, deterioration effect, Internet-based guided self-help, negative effects.

* Address for correspondence: D. D. Ebert, Ph.D., Friedrich Alexander University Erlangen-Nuremberg, Erlangen, Germany. (Email: david.ebert@fau.de)

\section{Introduction}

Major depressive disorder (MDD) is not only highly prevalent (Alonso et al. 2004; Waraich et al. 2004; Kessler et al. 2005; Wittchen et al. 2011; Rozental et al. 2014) but also associated with substantial impairment 
(Ustün et al. 2004; Saarni et al. 2007) and economic costs (Berto et al. 2000; Greenberg \& Birnbaum, 2005; Smit et al. 2006).

Psychological treatments have been shown to be effective in the treatment of depression (Cuijpers et al. $2008 a$, 2014). However, not all benefit from these treatments and many affected individuals remain untreated (Kohn et al. 2004; Wittchen et al. 2011).

Internet-based guided self-help interventions might be an acceptable (Cavanagh et al. 2011), effective (Johansson \& Andersson, 2012; Richards \& Richardson, 2012), and cost-effective (Hedman et al. 2012) treatment alternative, that could provide treatment to individuals not reached so far (Ebert et al. 2015a). While researchers have consistently demonstrated positive effects of Internet-based guided self-help for depression both, for adults (Richards \& Richardson, 2012) and youths (Ebert et al. 2015b), little is known about potential negative effects of Internet-based psychological treatments for depression (Boettcher et al. 2014; Ebert et al. 2014a; Rozental et al. 2014). This is not unique for Internet treatments, as limited data are also available regarding negative effects for psychotherapy in general (Barlow, 2010; Emmelkamp et al. 2014).

While in pharmacological outcome research the standard is to always evaluate both risks and benefits of an intervention (Willan et al. 1997; Curtin \& Schulz, 2011) psychotherapy outcome research has so far mostly focused on treatment benefits only (Lilienfeld, 2007; Dimidjian \& Hollon, 2010).

Among different potential negative effects of psychotherapy one particularly unfavorable outcome is deterioration of symptoms as a consequence of treatment. Evidence from uncontrolled psychotherapy outcome studies indicates that a substantial number of patients experience a symptom deterioration while being in psychotherapy. The proportion of patients with symptom deterioration in these uncontrolled studies range from 3\% to 14\% (Smith \& Glass, 1977; Mohr, 1995; Hansen et al. 2006; Lambert et al. 2006). This phenomenon of 'the deterioration effect' has been noted even in the early years of psychotherapy research (Bergin, 1966; Garfield et al. 1971).

With regard to Internet-based self-help treatments, it could be argued that such interventions may be associated with an even greater risk for symptom deterioration than face-to-face approaches. For example, for some individuals a self-help approach might not be intense enough (Kiluk et al. 2011). Further, individuals might be overstrained by trying to apply psychotherapeutic self-help strategies. Some therapeutic techniques could be inappropriately implemented by participants without direct guidance from a therapist. These problems could result in a further aggravation of hopelessness in severely affected individuals. It could also be argued that in face-to-face treatments it is much easier to observe and react to early signs of deterioration than it is via the Internet. Another potential negative effect could be that self-help treatments could lead to a delayed help-seeking, which could result in a further deterioration of symptoms, if the initial low-intensity self-help treatment should be not sufficient.

Despite the fact that the topic of potential negative effects of both Internet-based treatments (Kiluk et al. 2011; Boettcher et al. 2014; Rozental et al. 2014, 2015; Bengtsson et al. 2015) and face-to-face psychotherapy (Lilienfeld, 2007; Barlow, 2010; Dimidjian \& Hollon, 2010; Linden, 2013; Ladwig et al. 2014) have recently gained attention in the literature, empirical evidence on potential negative effects drawn from randomized controlled trials (RCTs) is still almost absent (Lilienfeld, 2007).

RCTs are the most reasonable approach to determine whether a treatment is differentially associated with a deterioration in functioning or an increase in symptomatology (Dimidjian \& Hollon, 2010). If a randomized trial shows that participants in the active condition show greater deterioration in functioning than those in the non-treatment control condition, one can confidently conclude that the deterioration was a consequence of therapy (Lilienfeld, 2007). However, given that the number of people deteriorating during treatment is expected to be small, randomized trials are mostly underpowered to examine this research question adequately.

Moreover, RCTs evaluating psychological treatments seldom report the number of patients who deteriorated during treatment, thus it is not possible to investigate mean deterioration effects found in randomized trials and its moderators using traditional meta-analytical approaches. Consequently, to the best of our knowledge, there is no meta-analytical review on symptom deterioration and its moderators within RCTs evaluating Internet-based treatments or psychological interventions for depression in general. Given the increasing popularity of Internet-based treatments in healthcare systems worldwide (Andersson et al. 2014), there is a pressing need to evaluate potential deterioration effects of Internet-based treatments.

Individual participant data meta-analysis (IPDMA) can overcome some of the limitations of conventional meta-analysis at the study level (Clarke, 2005; Riley et al. 2010). By collecting and pooling the primary data of individual trials, analyses can be conducted, which have not been reported in the original studies. Furthermore, trials designed to detect overall treatment effects have limited power to detect treatment $\times$ subgroup interactions (Brookes et al. 2004). By combining the primary data of multiple trials using an IPDMA approach, it is possible to obtain a large sample size with sufficient power to examine effects in relevant 

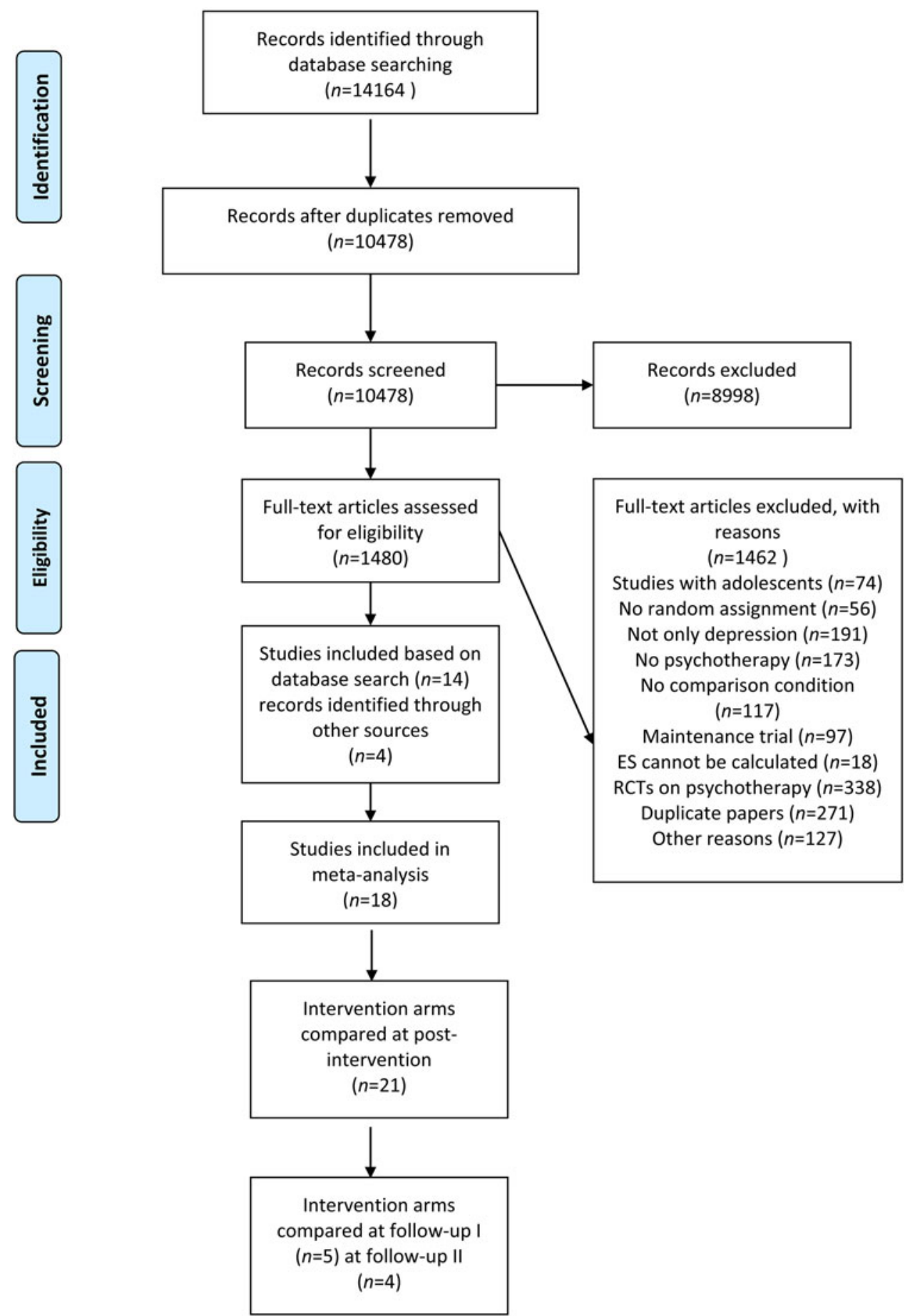

Fig. 1. Flowchart inclusion of studies.

subgroups and identify moderators of outcome (Cooper \& Patall, 2009).

Hence, the present study aims to investigate deterioration rates and moderators of deterioration within randomized trials on Internet-based guided self-help interventions for adult depression, using IPDMA. We also evaluated deterioration rates in a number of subgroups of interest.

\section{Method}

\section{Identification and selection of studies}

In this study, we included randomized trials in which the effects of an Internet-based guided self-help treatment were compared with a control or comparison group (waiting list, care-as-usual, other) in adults (aged $\geqslant 18$ years) with depression (established by 
diagnostic interview or elevated levels of depressive symptoms based on self-report measures). Studies were excluded if study participants were not currently in a depressive episode (e.g. if they were in remission), if the interventions were provided without guidance (i.e. without support from a therapist or other healthcare professional) in order to increase internal validity and to reduce potential heterogeneity, if the interventions were delivered to the individual via a group format or were delivered at a location that required the individual to travel to use the programme (e.g. a clinic). Co-morbid general medical or psychiatric disorders were not used as a study exclusion criterion. No language restrictions were applied. Fig. 1 shows the selection process for included studies.

For the identification of potential studies for inclusion, we used a database of 1476 papers on the psychological treatment of depression that has been described in detail elsewhere (Cuijpers et al. 2008b). These searches covered papers published until January 2014 and in these searches we examined 14164 abstracts in Pubmed (3638 abstracts), PsycInfo (2824), EMBASE (4682), and the Cochrane Central Register of Controlled Trials (3020). These abstracts were identified by combining terms indicative of psychological treatment and depression (both $\mathrm{MeSH}$ terms and text words). Further, the primary studies from 42 meta-analyses of psychological treatment for depression were checked to ensure that no published studies were missed. From the 14164 abstracts (10 474 after removal of duplicates) 1476 full-text papers were retrieved for possible inclusion in the database.

\section{Data collection, characteristics of included studies and participants}

Corresponding authors were contacted for each of the identified papers and asked to provide raw data from their study. Of the 15 published studies identified from the database search, primary data was obtained from 14 (Andersson et al. 2005; van Straten et al. 2008; Warmerdam et al. 2008; Perini et al. 2009; Ruwaard et al. 2009; Vernmark et al. 2010; Titov et al. 2010; Berger et al. 2011; van Bastelaar et al. 2011; Choi et al. 2012; Johansson et al. 2012a, b; Sheeber et al. 2012; Ünlü Ince et al. 2013). Data for one study (Titov et al. 2011) could not be obtained, as the dataset was no longer available to the Titov research team. The study that was not included did not differ from the other studies in terms of design, participants, intervention, or quality. We also asked all authors whether they were aware of other recently completed RCTs that met our inclusion criteria, but were not yet published. Four more studies were identified by this method, and the authors were all willing to contribute their primary data to this project (Carlbring et al. 2013; Newby et al. 2013; Ebert et al. 2014c; Kleiboer et al. 2015). This process resulted in a dataset with the primary data from 18 RCTs including 2079 cases. These 18 randomized controlled studies included 21 comparisons between an Internet-based guided self-help group $v$. control condition from baseline to post-test, five comparisons in addition from baseline to follow-up I (1-4 months, mean $=2.44$, s.D. $=1.09$, range $1-4, n=737$ participants) and four comparisons from baseline to follow-up 2 ( $\geqslant 6$ months, mean $=6.96$, s.D. $=1.7$, range $6-10, n=594$ participants). If a study had three conditions there would be two comparisons (i.e. the active treatment condition with each of the two control conditions). Only one study provided data for both follow-up time points (Ebert et al. 2014b). Characteristics of each included study are described in Table 1. Detailed information on sociodemographic and clinical characteristics of study participants can be found in Table 2.

\section{Risk of bias assessment}

The validity of included studies was assessed using four criteria of the 'Risk of Bias' assessment tool, developed by the Cochrane Collaboration (Higgins et al. 2011). This tool assesses possible sources of bias in randomized trials, including the adequate generation of allocation sequence; the concealment of allocation to conditions; the prevention of knowledge of the allocated intervention (masking of assessors); and dealing with incomplete outcome data (this was assessed as positive when intention-to-treat (ITT) analyses were conducted, meaning that all randomized participants were included in the analyses). Assessment of the quality was conducted independently by two assessors. Overall risk of bias was low. All studies reported an adequate sequence generation, and allocation to conditions by an independent (third) party. Sixteen studies reported blinding of outcome assessors or used only self-report outcomes, whereas five did not report blinding. All studies were coded as having handled missing data adequately, as ITT analyses were applied and missing data were imputed for all studies using multiple imputation. Sixteen studies met all four quality criteria, the remaining five studies met three of four criteria. Agreement between independent raters (P.C., L.D.) on the risk of bias was $95 \%$ across studies.

\section{Missing data}

Analyses were conducted according to the ITT principle. Missing data in the raw datasets were handled using multiple imputations (Schafer \& Graham, 2002) with a Markov Chain Monte Carlo multivariate imputation algorithm (Missing data module in SPSS v. 20; 
Table 1. Selected characteristics of randomized controlled studies examining the effects of Internet-based psychotherapies for depression in adults

\begin{tabular}{|c|c|c|c|c|c|c|c|c|c|c|c|c|c|c|}
\hline Study & Recr & Depression & Inter-vention & $N_{\bmod }$ & $\begin{array}{l}\text { Time } \\
\text { (weeks) }\end{array}$ & Guidance & $N$ & Control group & $N$ & $\begin{array}{l}\text { Primary } \\
\text { outcome }\end{array}$ & $\begin{array}{l}\text { Duration of } \\
\text { follow-up }\end{array}$ & Qual $^{\mathrm{a}}$ & Publ & Country \\
\hline $\begin{array}{l}\text { 1. Andersson et al. } \\
\text { (2005) }\end{array}$ & Comm & $\begin{array}{l}\text { MDD on CIDI-SF + } \\
\text { MADRS-S 15-30 }\end{array}$ & CBT & 5 & 8 & $\begin{array}{l}\text { Feedback at the end of each } \\
\text { module }\end{array}$ & 62 & $\begin{array}{l}\text { Web-based } \\
\text { discussion } \\
\text { group }\end{array}$ & 62 & BDI-II & 6 months & ++++ & 1 & SWE \\
\hline $\begin{array}{l}\text { 2. Berger et al. } \\
\text { (2011) }\end{array}$ & Comm & $\begin{array}{l}\text { MDD on MINI + } \\
\text { BDI-II }>13\end{array}$ & CBT & 11 & 12 & $\begin{array}{l}\text { Weekly support via email by } \\
\text { therapist }\end{array}$ & 25 & WL & 26 & BDI-II & 6 months & ++++ & 1 & $\begin{array}{r}\text { SWZ/ } \\
\text { GER }\end{array}$ \\
\hline $\begin{array}{l}\text { 3. Carlbring et al. } \\
\text { (2013) }\end{array}$ & Comm & $\begin{array}{l}\text { MDD on MINI-DIS + } \\
\text { PS BDI-II >13 }\end{array}$ & ACT & 7 & 13 & $\begin{array}{l}\text { Weekly contact by } \\
\text { psychologist }\end{array}$ & 40 & WL & 40 & BDI-II & - & ++++ & 0 & SWE \\
\hline $\begin{array}{l}\text { 4. Choi et al. } \\
\text { (2012) }\end{array}$ & Comm & $\begin{array}{l}\text { MDD on SCID-I } \\
\text { PHQ-9 score }>18\end{array}$ & CBT & 6 & 8 & $\begin{array}{l}\text { Weekly support via email or } \\
\text { telephone by therapist }\end{array}$ & 25 & WL & 30 & BDI & N.A. & ++-+ & 1 & $\mathrm{AU}$ \\
\hline 5. Ebert $(2014 b)$ & Comm & CES-D > 16 & PST & 5 & 5 & $\begin{array}{l}\text { Feedback at the end of each } \\
\text { module }\end{array}$ & 75 & WL & 75 & CES-D & $\begin{array}{l}3 \text { and } 6 \\
\text { months }\end{array}$ & ++++ & 0 & GER \\
\hline $\begin{array}{l}\text { 6. Johansson \& } \\
\text { Andersson } \\
(2012 a)\end{array}$ & $\begin{array}{l}\text { Comm/ } \\
\text { Clin }\end{array}$ & $\begin{array}{l}\text { MADRS-S 15-35 } \\
\text { MDD confirmed by } \\
\text { telephone interview }\end{array}$ & $\mathrm{PD}$ & 9 & 10 & $\begin{array}{l}\text { Contact via online platform } \\
\text { by therapist }\end{array}$ & 46 & $\begin{array}{l}\text { Brief scheduled } \\
\text { therapist } \\
\text { support }\end{array}$ & 46 & BDI-II & 10 months & ++-+ & 1 & SWE \\
\hline $\begin{array}{l}\text { 7. Johansson \& } \\
\text { Andersson } \\
(2012 b)^{a}\end{array}$ & $\begin{array}{l}\text { Comm/ } \\
\text { Clin }\end{array}$ & $\begin{array}{l}\text { MADRS-S >14 MDD } \\
\text { on SCID-I }\end{array}$ & $\mathrm{CBT}^{*}$ & $8-10$ & 10 & $\begin{array}{l}\text { Contact via email by } \\
\text { therapist }\end{array}$ & 36 & $\begin{array}{l}\text { Moderated } \\
\text { web-based } \\
\text { discussion } \\
\text { group }\end{array}$ & 42 & BDI-II & N/A & ++++ & 1 & SWE \\
\hline 8. Kleiboer (2015) & Comm & $\begin{array}{l}\text { CES-D score of 16-39 } \\
\text { HADS score of 8-14 }\end{array}$ & PST & 5 & 5 & Contact via email by coach & 106 & WL & 106 & CES-D & N.A. & +++ & 0 & NL \\
\hline $\begin{array}{l}\text { 9. Newby et al. } \\
\text { (2013) }\end{array}$ & $\begin{array}{l}\text { Comm/ } \\
\text { Clin }\end{array}$ & MDD on MINI & СBT & 6 & 10 & $\begin{array}{l}\text { Regular contact up to session } \\
\text { 2, and response to user } \\
\text { requests or decline in K10/ } \\
\text { PHQ-9 scores }\end{array}$ & 25 & WL & 37 & BDI-II & N.A. & ++-+ & 1 & $\mathrm{AU}$ \\
\hline $\begin{array}{l}\text { 10. Perini et al. } \\
\text { (2009) }\end{array}$ & Comm & PHQ-9 score >4 & CBT & 6 & 6 & $\begin{array}{l}\text { Contact via email by } \\
\text { therapist }\end{array}$ & 27 & WL & 18 & BDI-II & N.A. & +++ & 1 & $\mathrm{AU}$ \\
\hline $\begin{array}{l}\text { 11. Ruwaard et al. } \\
\text { (2009) }\end{array}$ & Comm & BDI-IA score 10-29 & CBT & 8 & 11 & $\begin{array}{l}\text { Feedback on activities by } \\
\text { therapist }\end{array}$ & 36 & WL & 18 & BDI-IA & N.A. & ++++ & 1 & NL \\
\hline $\begin{array}{l}\text { 12. Sheeber } \text { et al. } \\
\text { (2012) }\end{array}$ & Clin & $\begin{array}{l}\text { Elevated self-reported } \\
\text { levels of depression }\end{array}$ & СBT & 8 & 8 & Weekly contact via telephone & 35 & WL & 35 & BDI-II & N.A. & ++++ & 1 & USA \\
\hline \multirow[t]{2}{*}{$\begin{array}{l}\text { 13. Titov et al. } \\
(2010)^{\mathrm{a}}\end{array}$} & Comm & MDD on MINI & CBT & 8 & 8 & Weekly contact by therapist & 38 & WL & 36 & BDI-II & N.A. & ++++ & 1 & $\mathrm{AU}$ \\
\hline & & & CBT & 8 & 8 & & 45 & & & & & & & \\
\hline $\begin{array}{l}\text { 14. Ünlü Ince } \\
\text { (2013) }\end{array}$ & Comm & $\begin{array}{l}\text { MDD on MINI CES-D } \\
>15\end{array}$ & PST & 5 & 5 & $\begin{array}{l}\text { Feedback on homework } \\
\text { activities by coach }\end{array}$ & 49 & WL & 47 & CES-D & 4 months & +++ & 0 & NL \\
\hline
\end{tabular}


Table 1 (cont.)

\begin{tabular}{|c|c|c|c|c|c|c|c|c|c|c|c|c|c|c|}
\hline Study & Recr & Depression & Inter-vention & $N_{\text {mod }}$ & $\begin{array}{l}\text { Time } \\
\text { (weeks) }\end{array}$ & Guidance & $N$ & Control group & $N$ & $\begin{array}{l}\text { Primary } \\
\text { outcome }\end{array}$ & $\begin{array}{l}\text { Duration of } \\
\text { follow-up }\end{array}$ & Qual $^{\mathrm{a}}$ & Publ & Country \\
\hline $\begin{array}{l}\text { 15. Van Bastelaar } \\
\text { et al. (2011) }\end{array}$ & Comm & $\begin{array}{l}\text { MDD on CIDI CES-D } \\
>15\end{array}$ & CBT & 8 & 8 & $\begin{array}{l}\text { Feedback on homework } \\
\text { activities by coach }\end{array}$ & 125 & WL & 130 & CES-D & 1 month & ++-+ & 1 & NL \\
\hline $\begin{array}{l}\text { 16. Van Straten } \\
\text { et al. (2008) }\end{array}$ & Comm & $\begin{array}{l}\text { Self-defined } \\
\text { depression or } \\
\text { anxiety }\end{array}$ & PST & 4 & 4 & Feedback by coach & 107 & WL & 106 & CES-D & N.A. & ++++ & 1 & NL \\
\hline $\begin{array}{l}\text { 17. Vernmark } \\
\text { et al. (2010) }\end{array}$ & Comm & MDD on SCID-I-CV & СBT & 7 & 7 & $\begin{array}{l}\text { Support via email by } \\
\text { therapist }\end{array}$ & 29 & WL & 29 & BDI & N/A & ++-+ & 1 & SW \\
\hline \multirow[t]{2}{*}{$\begin{array}{l}\text { 18. Warmerdam } \\
\text { et al. }(2008)^{\mathrm{a}}\end{array}$} & Comm & CES-D* & CBT & 8 & 8 & $\begin{array}{l}\text { Weekly feedback by } \\
\text { therapist }\end{array}$ & 88 & WL & 87 & CES-D & 3 months & ++++ & 1 & NL \\
\hline & & & PST & 5 & 8 & & 88 & & & & & & & \\
\hline
\end{tabular}

Recr, Recruitment population; Comm, Community sample; Clin, Clinical Sample; Depression, confirmation of depression; CBT, cognitive behaviour therapy; ACT, acceptance and

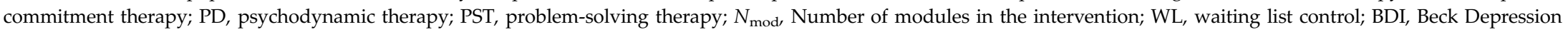
Inventory; CES-D, Centre for Epidemiology Studies Depression Scale; Qual, risk of bias Score; Publ, publication of result $(0=$ unpublished, $1=$ published); SWE, Sweden; SWZ, Switzerland; GER, Germany; NL, The Netherlands; AU, Australia; USA, United States of America.

${ }^{a}$ In this column a positive or negative sign is given for four quality criteria, respectively: allocation sequence; concealment of allocation to conditions; blinding of assessors; and intention-to-treat analyses. 
Table 2. Demographic and clinical characteristics

\begin{tabular}{|c|c|c|c|c|c|c|c|c|c|}
\hline & \multicolumn{3}{|c|}{ Intervention $(N=1123)$} & \multicolumn{3}{|c|}{ Control $(N=956)$} & \multicolumn{3}{|l|}{ All $(N=2079)$} \\
\hline & $\%$ & Mean & S.D. & $\%$ & Mean & S.D. & $\%$ & Mean & S.D. \\
\hline Age, years & & 47.1 & 8.2 & & 46.4 & 9.2 & & 47.8 & 7.3 \\
\hline Female $(\%)$ & $789(70.57)$ & & & $640(66.04)$ & & & $1419(68.48)$ & & \\
\hline Married/partnership (\%) & $442(49.44)$ & & & $378(47.61)$ & & & $820(48.58)$ & & \\
\hline Further education after high school (\%) ${ }^{\mathrm{a}}$ & $548(59.05)$ & & & $404(54.16)$ & & & $952(56.87)$ & & \\
\hline \multicolumn{10}{|l|}{$\mathrm{BDI}^{\mathrm{b}}$} \\
\hline Baseline & & 25.19 & 8.26 & & 24.57 & 8.14 & & 24.91 & 8.21 \\
\hline Post & & 13.24 & 8.98 & & 21.01 & 10.09 & & 16.78 & 10.26 \\
\hline \multicolumn{10}{|l|}{ Follow-up I ${ }^{\mathrm{c}}$} \\
\hline Follow-up II & & 12.23 & 8.25 & & 14.52 & 8.81 & & 13.39 & 8.6 \\
\hline \multicolumn{10}{|l|}{ CES-D ${ }^{\mathrm{b}}$} \\
\hline Baseline & & 28.86 & 8.4 & & 28.46 & 8.42 & & 28.67 & 8.41 \\
\hline Post & & 16.83 & 11.23 & & 23.05 & 10.34 & & 19.88 & 11.23 \\
\hline Follow-up I & & 17.80 & 8.75 & & 22.72 & 8.34 & & 20.05 & 8.91 \\
\hline Follow-up II & & 14.91 & 9.65 & & 20.12 & 9.79 & & 17.62 & 10.03 \\
\hline No current use of antidepressants ${ }^{a}$ & $27(4.48)$ & & & $11(2.05)$ & & & $38(3.34)$ & & \\
\hline Comorbid anxiety disorder $(\%)^{\mathrm{a}}$ & $308(57.36)$ & & & $288(58.06)$ & & & $596(57.7)$ & & \\
\hline
\end{tabular}

BDI, Beck Depression Inventory; CES-D, Centre for Epidemiological Studies Depression Scale.

a Percentages refer to those participants of studies who reported data.

${ }^{\mathrm{b}}$ Medication: BDI and CES-D data refer to the imputed values.

'Studies that used the BDI as primary outcome did not assess follow-up I.

IBM Corp., USA) and 100 estimations per missing value. For the imputation of the primary outcome depression severity, we used all complete participant and study characteristics (study identifier, intervention group, baseline depression score, age, sex, recruitment population, confirmation of depression diagnosis method, intervention type, country of study, bias score - and post-intervention depression score when imputing follow-up). We did not impute baseline predictors.

\section{Calculating deterioration rates}

All studies used either the Centre for Epidemiological Studies - Depression Scale (CES-D; Radloff, 1977), or the Beck Depression Inventory (BDI; Beck et al. 1961) as outcome measures. Where multiple depression measures were present, the BDI was coded as the primary outcome measure given that it was the most frequently used outcome measure across studies. For both measures we calculated deterioration and response rates according to the widely used reliable change index (RCI; Jacobson \& Truax, 1991). Participants whose scores from pre-treatment to post-treatment had RCIs below the cut point of -1.96 were considered to have experienced deterioration. A RCI of -1.96 is equivalent to increases of depression of 7.68 points on the CES-D; and 7.63 points on the BDI.

\section{Analyses}

Effects of Internet-based treatments on deterioration rates were calculated using the standard two-step IPDMA approach (Riley et al. 2010). Thus, after calculating whether or not a participant deteriorated (yes/ no) we calculated event rates for each study separately on the basis of the imputed data. Following this, pooled event rates across studies were calculated according to a random-effects model as implemented in the Comprehensive Meta-analysis software package version 2.2.021 (https://www.meta-analysis.com), accounting for clustering of both participants' withinstudy and between-study heterogeneity (Abo-Zaid et al. 2013). We proceeded by calculating the relative risks for each study, and pooled the results across the studies using a random-effects DerSimonian-Laird model (DerSimonian \& Laird, 1986). For all analyses we chose a random-effects model, as we expected considerable heterogeneity among the studies. If there were significant differences between the groups with regard to deterioration, response, and remission rates, we also calculated the number needed to harm $(\mathrm{NNH})$ and/or the number needed to treat (NNT) 
and the associated 95\% confidence intervals (CIs), compared to the control group. The NNH indicates the number of participants treated in the experimental condition for one extra person to demonstrate symptom deterioration as compared to the control group. We also calculated a benefit-risk ratio (Willan et al. 1997), by dividing the NNH for one extra symptom deterioration through the NNT to achieve one response [response was also defined using the reliable change criteria, such that participants with a reliable positive change $(+1.96$ on the RCI) were considered responders]. This procedure is usually used within drug treatment research (Curtin \& Schulz, 2011), and quantifies the numbers of favourable outcomes achieved for each additional unfavorable outcome event incurred. Benefit-risk ratios were only calculated if there is a higher risk of deterioration in the intervention group as compared to the control group (Willan et al. 1997).

\section{Sensitivity analyses}

To test the robustness of our findings, we also conducted a sensitivity analysis applying an alternative criterion for deterioration. We defined the alternative criterion for deterioration such that individuals whose depression scores at baseline increased by $\geqslant 50 \%$ at follow-up were categorized as having experienced deterioration. This criterion refers to a relative change instead of to an absolute change in symptoms.

\section{Multiple treatments within one study}

There were three studies in which two treatments were compared with a single control group (Warmerdam et al. 2008; Titov et al. 2010; Johansson et al. 2012b). In these cases, we treated each comparison as a separate study, and we avoided double counting of controls by randomly assigning half the control participants to each comparison.

\section{Heterogeneity}

As a test of homogeneity of effect sizes, we calculated the $I^{2}$ statistic as an indicator of heterogeneity in percentages (Ioannidis et al. 2007). A value of $0 \%$ indicates no observed heterogeneity, and larger values indicate increasing heterogeneity, with $25 \%$ as low, $50 \%$ as moderate, and $75 \%$ as high heterogeneity. We calculated 95\% CIs around relative risks (RRs), using the non-central $\chi^{2}$-based approach within the heterogi module for Stata (Orsini et al. 2013). We also calculated the $Q$ statistic, but only report whether this was significant.

\section{Publication bias}

Publication bias was tested by inspecting the funnel plot and by Egger's test (Egger et al. 1997). We also applied Duval \& Tweedie's trim-and-fill procedure (Duval \& Tweedie, 2000), which yields an estimate of the effect size after the publication bias has been taken into account (Borenstein et al. 2009).

\section{Subgroup analyses}

We conducted a series of subgroup analyses. Pooling of the results was conducted according to the mixed-effects model. In this model, studies within subgroups are pooled with the random-effects model, while tests for significant differences between subgroups are conducted with the fixed-effects model. Subgroup analyses were only conducted for posttreatment data and not for follow-up data, as the sample sizes of follow-up datasets were not large enough to test for significant differences between subgroups. The following subgroups were investigated: Participant characteristics: sex (male/female); age group [adults (18-59 years), older adults ( $\geqslant 60$ years)]; education [low (up to high school), medium to high (high school degree or further education after high school)]; co-morbid anxiety disorder (yes/no); depression severity at baseline [mild to moderate (BDI $<29)$; severe (BDI $\geqslant 29)$ ]; depression severity at baseline subgroup analyses was only calculated for participants of studies using the BDI, as the CES-D does not have an established cut-off score for depression severity. Study characteristics: MDD confirmed using an established diagnostic interview (yes/no); recruitment (community, clinical setting); risk of bias score [low (4); some risk $(<4)$ ]; type of control group (non-active/active). Intervention characteristics: theoretical model of the intervention (CBT, other); number of modules (4-5, 6-7, 8-11).

\section{Ethical standards}

The authors assert that all procedures contributing to this work comply with the ethical standards of the relevant national and institutional committees on human experimentation and with the Helsinki Declaration of 1975, as revised in 2008.

\section{Results}

\section{Deterioration rates}

Overall pooled reliable deterioration rates across measurements are summarised in Table 3 . The risk for a reliable deterioration from baseline to post-treatment was significantly lower in the intervention $v$. control conditions (RR 0.47, 95\% CI 0.29-0.75) and the NNT 
Table 3. Deterioration rates in Internet-based treatments of depression, sensitivity, and subgroup analyses

\begin{tabular}{|c|c|c|c|c|c|c|c|c|c|}
\hline & & $N_{\mathrm{co}}$ & $\mathrm{ER}_{\mathrm{IG}}(95 \% \mathrm{CI})$ & $\mathrm{ER}_{\mathrm{CG}}(95 \% \mathrm{CI})$ & RR (95\% CI) & Z & $I^{2}(95 \% \mathrm{CI})$ & $\begin{array}{l}\text { NNT/NNH } \\
(95 \% \text { CI })^{\mathrm{a}}\end{array}$ & $p^{\mathrm{b}}$ \\
\hline Deterioration rates & Post-treatment & 21 & $3.36(2.5-5)$ & $7.6(5.59-9.70)$ & $0.47(0.29-0.75)$ & $-3.17^{* *}$ & $0(0-50)$ & 43.21 (25.83 to 132.10$)$ & \\
\hline \multirow[t]{2}{*}{$(\mathrm{RCI})$} & Follow-up I & 5 & $2.80(2.5-5)$ & $6.10(2.9-12.3)$ & $0.47(0.20-1.42)$ & $-1.66+$ & $0(0-79)$ & 71.43 (21.28 to -52.63$)$ & \\
\hline & Follow-up II & 4 & $6.0(3.3-10.7)$ & $5.30(2.8-9.8)$ & $1.17(0.49-2.87)$ & 0.35 & $0(0-90)$ & $-142.86(30.3$ to -21.28$)$ & \\
\hline \multirow{3}{*}{$\begin{array}{l}\text { Alternative deterioration } \\
\text { criteria ( } 50 \% \text { increase) }\end{array}$} & Post-treatment & 21 & $3.12(2.09-4.62)$ & $5.20(3.64-7.37)$ & $0.51(0.29-0.86)$ & $-2.50^{* *}$ & $0(0-52)$ & 76.92 (38.46 to 1000$)$ & \\
\hline & Follow-up I & 5 & $2.35(0.75-7.14)$ & $4.36(1.96-9.42)$ & $0.70(0.28-1.75)$ & -0.76 & $0(0-85)$ & 111.11 (35.71 to -90.91$)$ & \\
\hline & Follow-up II & 4 & $3.92(1.93-7.83)$ & $4.37(2.28-8.19)$ & $0.83(0.30-2.27)$ & -0.37 & $0(0-90)$ & $100(22.22$ to -38.46$)$ & \\
\hline \multirow[t]{2}{*}{ Outcome measures separately } & Only BDI & 14 & $3.37(2.02-5.56)$ & $8.51(6.03-11.87)$ & $0.39(0.20-0.76)$ & $-2.75^{* *}$ & $0(0-58)$ & 27.03 (15.63 to 100$)$ & \\
\hline & Only CES-D & 7 & $3.09(1.52-6.16)$ & $5.57(3.12-9.74)$ & $0.56(0.29-1.11)$ & $-1.66+$ & $6.92(0-76)$ & 55.56 (23.81 to 200$)$ & \\
\hline \multicolumn{10}{|l|}{ Study characteristics } \\
\hline \multirow[t]{2}{*}{ Diagnosis } & Confirmed MDD & 11 & $3.63(2.09-6.23)$ & $8.07(5.50-11.70)$ & $0.42(0.21-0.85)$ & $-2.40^{*}$ & $0(0-60)$ & 23.26 (25.64 to 333.33$)$ & 0.17 \\
\hline & Depressive symptoms & 10 & $3.13(1.80-5.40)$ & $6.18(3.76-9.98)$ & $0.51(0.27-0.97)$ & $-2.06^{*}$ & $3.78(0-72)$ & 55.56 (13.51 to 83.33$)$ & \\
\hline \multirow[t]{2}{*}{ Target group } & General populations & 18 & $3.53(2.36-5.24)$ & $7.89(6.05-10.24)$ & $0.42(0.25-0.70)$ & $-3.36^{* * *}$ & $0(0-54)$ & 33.33 (20.83 to 83.33$)$ & 0.87 \\
\hline & Specific populations & 3 & $3.66(1.75-7.49)$ & $4.69(1.10-17.84)$ & $0.84(0.21-3.35)$ & -0.25 & $34.33(0-79)$ & 166.67 (14.93 to -18.18$)$ & \\
\hline \multirow[t]{2}{*}{ Recruitment } & Community recruitment & 16 & $3.81(2.61-5.53)$ & $6.64(4.69-9.33)$ & $0.53(0.32-0.89)$ & $-2.21^{*}$ & $0(0-57)$ & $52.63(28.57$ to 1000$)$ & 0.27 \\
\hline & Clinical samples & 5 & $2.28(0.86-5.92)$ & $9.46(5.67-15.37)$ & $0.26(0.09$ to -0.82$)$ & $-2.49^{*}$ & $0(0-79)$ & 16.67 (9.35 to 76.92$)$ & \\
\hline \multirow[t]{2}{*}{ Risk of bias score } & Some risk $(<4)$ & 5 & $2.42(1.09-5.27)$ & $6.62(3.33-12.72)$ & $0.50(0.18-1.39)$ & -1.32 & $0(0-79)$ & 27.78 (11.90 to -83.33$)$ & 0.89 \\
\hline & Low (4) & 16 & $3.92(2.64-5.77)$ & $7.70(5.71-10.32)$ & $0.47(0.28-0.78)$ & $-2.88^{* *}$ & $0(0-57)$ & 40 (23.26 to 166.67$)$ & \\
\hline \multirow[t]{2}{*}{ Type of control } & Active & 4 & $3.50(1.52-7.83)$ & $5.45(2.75-10.53)$ & $0.60(0.20-1.76)$ & -0.94 & $0(0-85)$ & $40(14.08$ to -47.62$)$ & 0.21 \\
\hline & Non-active & 17 & $3.57(2.42-5.24)$ & $7.52(5.39-10.39)$ & $0.45(0.27-0.75)$ & $-3.06^{* *}$ & $0(0-55)$ & $38.46(22.22$ to 142.86$)$ & \\
\hline \multicolumn{10}{|l|}{ Intervention characteristics } \\
\hline \multirow[t]{2}{*}{ Intervention type } & CBT & 14 & $3.14(1.96-5.00)$ & $7.41(5.07-10.71)$ & $0.46(0.25-0.87)$ & $-2.39 * *$ & $0(0-58)$ & 45.45 (22.73 to 2953.11$)$ & 0.91 \\
\hline & Other & 7 & $3.35(1.60-6.90)$ & $7.05(4.50-10.89)$ & $0.49(0.25-0.96)$ & $-2.08^{*}$ & $0(0-75)$ & 37.04 (18.52 to -2821.37$)$ & \\
\hline \multirow[t]{3}{*}{ No. of modules } & $4-5$ & 8 & $4.23(2.43-7.28)$ & $7.33(4.69-11.29)$ & $0.58(0.30-0.54)$ & -1.69 & $1.65(0-71)$ & 43.48 (19.23 to -166.67$)$ & 0.51 \\
\hline & $6-7$ & 3 & $1.61(0.33-7.60)$ & $7.59(3.55-15.50)$ & $0.18(0.02-1.44)$ & -1.62 & $0^{\mathrm{c}}$ & $22.73(10$ to -90.91$)$ & \\
\hline & $8-11$ & 10 & $2.85(1.64-4.91)$ & $6.90(4.27-10.95)$ & $0.41(0.20-0.84)$ & $-2.42^{*}$ & $0(0-65)$ & 45.45 (21.74 to -333.33$)$ & \\
\hline \multicolumn{10}{|l|}{ Patient characteristics } \\
\hline \multirow[t]{2}{*}{ Depression Severity } & Mild-moderate & 14 & $4.38(2.53-7.48)$ & $11.09(7.43-16.23)$ & $0.45(0.23-0.94)$ & $-2.12^{*}$ & $0(0-60)$ & 41.67 (17.24 to 90.91$)$ & 0.77 \\
\hline & Severe & 14 & $5.37(2.57-10.88)$ & $9.20(5.00-16.33)$ & $0.36(0.09-1.36)$ & -1.51 & $0(0-79)$ & 31.25 (11.11 to 38.46$)$ & \\
\hline \multirow[t]{2}{*}{ Anxiety disorder } & Yes & 9 & $2.99(1.50-5.87)$ & $5.72(3.47-9.28)$ & $0.41(0.16-1.01)$ & $-1.87+$ & $0(0-54)$ & 28.34 (15.31 to 190.53$)$ & \\
\hline & No & 9 & $3.66(1.70-7.69)$ & $5.55(2.84-10.56)$ & $0.66(0.22-1.97)$ & -0.75 & $0(0-83)$ & $238(25.36$ to -32.20$)$ & 0.52 \\
\hline \multirow[t]{2}{*}{ Age group } & Adults & 21 & $3.51(2.44-5.03)$ & $7.97(6.05-10.43)$ & $0.46(0.48-0.28)$ & $-3.12^{* *}$ & $0(0-50)$ & 45.45 (24.39 to 250$)$ & 0.84 \\
\hline & Old adults $(\geqslant 60)$ & 19 & $7.56(3.63-15.11)$ & 10.67 (5.75-18.97) & $0.39(0.09-1.70)$ & -1.25 & $0(0-85)$ & $24.39(9.17$ to -38.46$)$ & \\
\hline
\end{tabular}


to avoid one additional deterioration was 43.21 (95\% CI 25.83-132.10). Heterogeneity was zero. The risk of a deterioration from baseline to follow-up I (1-4 months) appeared to demonstrate a trend towards being lower in the intervention groups compared to the control groups (RR 0.47, 95\% CI 0.20-1.42), although the difference did not reach statistical significance $(p=0.097)$. There were no significant differences between the groups in the relative risk of a deterioration from baseline to follow-up II $(p=0.72)$. Heterogeneity was zero at both follow-ups.

Sensitivity and subgroup analyses are presented in Table 3. Applying the alternative deterioration criteria ( $50 \%$ symptom increase) resulted in slightly lower deterioration rates, but demonstrated a similar overall pattern.

Effects of Internet-based treatments compared to control conditions on deterioration rates at posttreatment were non-significant $(p>0.05)$ in 11 out of 25 subgroups tested and showed significantly better outcomes for those in Internet-based treatment in 14 out of 25 subgroups tested. RR was higher among those in Internet-based treatments than those in control conditions in only one subgroup (i.e. those with low education), although this difference was not significant (RR 1.72, NNH 30.3, 95\% CI -26.32 to $9.62, p=0.37$ ).

\section{Moderator of deterioration effects}

Education level was also the only significant moderator of treatment effects on deterioration, such that there was significantly higher risk for deterioration for participants with lower levels of educational attainment compared to those with more education. All other differences between subgroups on deterioration rates were non-significant $(p>0.10)$.

\section{Benefit-risk ratio}

Participating in Internet-based treatments for depression was not associated with an increased risk for deterioration when compared to a control group. There was only one subgroup analysis (i.e. participants with low levels of education) in which the relative risk for a deterioration was higher in the intervention group compared to the controls, although this difference was non-significant. Nonetheless, analyses of response rates at post treatment for the subgroup of participants with low education showed that their responses to treatment were significantly higher in the intervention group compared to controls, with a relative risk of 1.91 and a NNT to achieve one additional response of 3.23) (Ebert et al. unpublished data). Dividing the NNH in order that one symptom deterioration occurs through the NNT to achieve one treatment response, results in a benefit-risk ratio of 9.38, indicating that 9.38 participants with low education 
achieved a treatment response compared to the control group for each participant experiencing a deterioration in symptoms.

\section{Publication bias}

Inspection of the funnel plot and Egger's test indicated some possible publication biases. However, adjustment for publication bias using Duval \& Tweedie's trim-and-fill procedure did not result in substantial changes. After adjustment for missing studies (five imputed studies) the RR for deterioration by post-test was 0.58 (95\% CI 0.38-0.90), NNT were 43.21 (95\% CI 25.83-132.10). Results at both follow-ups stayed the same.

\section{Discussion}

This IPDMA evaluated deterioration rates of Internet-based guided self-help interventions for depression compared to control conditions in randomized trials. In addition, deterioration rates were evaluated in subgroups of interest and potential moderating effects were examined.

Results showed that overall deterioration rates were low and the risk of deterioration was significantly lower for participants in Internet-based guided self-help conditions compared to controls. Education significantly moderated the risk for deterioration such that participants with lower educational attainment displayed a higher risk of deterioration compared to participants with more education. Nonetheless, a risk-benefit ratio analysis indicated that also in the subgroup of participants with low education the likelihood of benefits of positive response to Internet-based treatment clearly outweigh the possible risk for deterioration.

To the best of our knowledge, the present study is the first meta-analysis that evaluated deterioration effects and its moderators in RCTs evaluating a psychological treatment. Observed deterioration effects are in the lower range $(3.6 \%)$ of those found in observational studies of face-to-face psychotherapy (3-14\%) (Strupp et al. 1977; Mohr, 1995; Hansen et al. 2006; Lambert et al. 2006). In contrast to early indications of possible adverse effects of psychological treatments (Bergin, 1966; Garfield et al. 1971), we did not find a deterioration effect as a consequence of therapy. Instead results indicate that participating in Internet-based guided self-help programmes is associated with a lower risk of deterioration (RR 0.47) relative to controls. This effect held for the overall group and most subgroups. However, education level was identified as a significant moderator, with low educated participants at a greater risk for a deterioration than highly educated participants. This finding corresponds to results from some randomized trials that found that lower educational attainment was associated with worse treatment outcomes compared to higher educated participants in Internet-based self-help interventions (Spek et al. 2008; Warmerdam et al. 2013). An explanation for such findings may be, that some patients with a lower educational level experience difficulties in terms of understanding the treatment modules, as most self-help manuals require a quite advanced reading comprehension. That may, in turn, decrease their selfefficacy and create feelings of hopelessness. Although all trials involved some form of guidance, this kind of support might not be sufficient for some individuals to overcome the barrier of low education. A more intensive treatment modality, as seeing a therapist face-to-face instead, could potentially help these patients understand the treatment rationale, and, thus, result in (hypothetically) less deterioration (Martinez et al. 2007). However, given that the topic of predictors of deterioration in psychotherapy has so far not been addressed in face-to-face psychotherapy, future studies should examine whether participants with a high risk for deterioration in Internet-interventions would be better suited for face-to-face psychotherapy. Another explanation may be that people with low education may also have other confounds (e.g. low income, poor physical health status, physical comorbidities, lower social support, less access to health services, etc.) which may either contribute to increased severity or lower ability to engage with the content/practice of skills from these programmes.

It should be noted, however, that deterioration rates of participants with low education $(10 \%)$ were still in the range of those found in observational studies on face-to-face psychotherapy (3-14\%, see above). Further, the benefit-risk ratio indicates that, in comparison to the control group, 9.38 patients with low education achieve a treatment response compared to the control group for each participant experiencing a deterioration in symptoms. It is also of note that with regard to response $v$. deterioration, a previously reported study using the same dataset did not find that education was a moderator of treatment response. Patients with low levels of education profited significantly and to almost the same extent (NNT=3.23 for response) as patients with more education (NNT $=3.25$ for response; Ebert et al. unpublished data). Thus, it is clear that most with low education experience response rather deterioration in Internet-based treatment. Therefore, low education alone should not be used to identify someone as high risk for deterioration and further research is needed to more specifically identify those who may be at high risk for deterioration.

When interpreting results from this study, several limitations need to be considered. First, the only negative effect evaluated was depression symptom deterioration. Other adverse effects may also occur and should be examined alongside RCTs in the context of 
Internet-based guided self-help interventions in the future. For example, providing less intensive treatment than necessary through a self-help intervention might lead to lower treatment expectation in participants who fail to achieve a treatment response (Ebert et al. 2014a). Hence, although the present study did not find indications for harm of Internet-based guided selfhelp interventions, the study design does not allow to conclude an absence of harm. For a complete discussion on negative effects in Internet-based psychotherapy see Rozental et al. (2014) and for psychological treatments in general see Linden (2013). Future studies should examine other potential harmful effects of Internet-based treatments alongside RCTs. Second, given the limited number of studies that included a follow-up assessment, both for the intervention and the control condition, the analyses were underpowered to adequately conduct subgroup and moderator analyses at follow-up. Third, although the total number of participants was very high (2079), the low number of participants per subgroup did not allow for an examination of the association between the intervention and participant-characteristics within subgroups. For example, given the result for education as a moderator, future studies should investigate predictors of deterioration in the subgroup of participants with low levels of education in order to differentiate between those participants with low education with high chances for treatment success and participants with low education at high risk for failure. Moreover, all programmes were only examined in one randomized trial. Hence we were not able to investigate potential negative effects of specific programmes, which should be done in future studies. Fourth, the present study only investigated guided treatments for depression, hence we can not conclude anything about potential negative effects of unguided self-help treatments. Fifth, given the nature of IPDMA, the examined moderators of outcome were limited to those assessed in the original randomized trials. There might be other relevant moderators that have been not assessed.

The present study has relevant implications for both clinical practice and research. First, the differential results for moderators of effects on deterioration and treatment response indicate that the chances and risks for positive and negative change in psychological treatments might be two distinct constructs. Thus future studies on the differential effectiveness of psychological treatments should investigate moderators of both outcomes separately, instead of only evaluating the effects on mean change scores as is commonly done in psychotherapy research. Second, while many healthcare systems hesitate to implement Internetbased guided self-help approaches, the present study indicates, that such interventions are not associated with an increased risk for deterioration, but instead reduces the risk for a further aggravation of symptoms. Taken together with findings showing that such interventions have substantial positive effects on mean symptom improvement and on treatment response and remission (Johansson \& Andersson, 2012; Ebert et al. 2015b) this further supports the need for dissemination of such treatments in routine mental health care. Nevertheless the moderator result for education indicates that a monitoring of participants with low education seems warranted, as they face an increased risk to deteriorate compared to participants with high education. Given that most participants with low education nevertheless achieve treatment response, and the mean effects on treatment response are comparable to those of participants with higher education, low education should not be used as an exclusion criteria in clinical practice. Instead, therapists should closely monitor the treatment and symptom progress in order to detect and react to early signs of a deterioration, e.g. by referral to more intensive treatment modalities. Given that the present study is the first study on deterioration rates in RCTs, one cannot conclude yet, whether these results are specific for Internet-based guided self-help intervention or whether such findings refer to psychological treatments for depression in general. Thus, future studies should evaluate deterioration rates and their moderators for face-to-face psychotherapy and should also compare overall and differential deterioration effects of internet-based and face-to-face psychotherapy.

The present study did not show any evidence for harm of Internet-based guided self-help interventions and indicates that such interventions reduce the risk for a symptom deterioration.

\section{Acknowledgements}

The European Union funded this study [EU EFRE: ZW667280119999, CCI 2007DE161PR001 \& FP7 E-Compared HEALTH.2013.3.1-1: Comparative Effectiveness Research CER in health systems and health services interventions (603098)].

\section{Declaration of Interest}

None.

\section{References}

Abo-Zaid G, Guo B, Deeks JJ, Debray TPA, Steyerberg EW, Moons KGM, Riley RD (2013). Individual participant data meta-analyses should not ignore clustering. Journal of Clinical Epidemiology 66, 865-873.

Alonso J, Angermeyer MC, Bernert S, Bruffaerts R, Brugha TS, Bryson H, de Girolamo G, Graaf R, Demyttenaere K, 
Gasquet I, Haro JM, Katz SJ, Kessler RC, Kovess V, Lépine JP, Ormel J, Polidori G, Russo LJ, Vilagut G, Almansa J, Arbabzadeh-Bouchez S, Autonell J, Bernal M, Buist-Bouwman MA, Codony M, Domingo-Salvany A, Ferrer M, Joo SS, Martínez-Alonso $M$, Matschinger $H$, Mazzi F, Morgan Z, Morosini P, Palacín C, Romera B, Taub N, Vollebergh WAM (2004). Prevalence of mental disorders in Europe: results from the European Study of the Epidemiology of Mental Disorders (ESEMeD) project. Acta Psychiatrica Scandinavica (Suppl.), 420, 21-27.

Andersson G, Bergström J, Holländare F, Carlbring P, Kaldo V, Ekselius L (2005). Internet-based self-help for depression: randomised controlled trial. British Journal of Psychiatry 187, 456-461.

Andersson G, Cuijpers P, Carlbring P, Riper H, Hedman E (2014). Guided Internet-based vs. face-to-face cognitive behavior therapy for psychiatric and somatic disorders: a systematic review and meta-analysis. World Psychiatry 13, 288-295.

Barlow DH (2010). Negative effects from psychological treatments: a perspective. American Psychologist 65, 13-20.

Beck AT, Ward CH, Mendelson M, Mock J, Erbaugh J (1961). An inventory for measuring depression. Archives of GeneralPpsychiatry 4, 561-571.

Bengtsson J, Nordin S, Carlbring P (2015). Therapists' experiences of conducting cognitive behavioural therapy online vis-à-vis face-to-face. Cognitive Behaviour Therapy 44, 470-479.

Berger T, Hämmerli K, Gubser N, Andersson G, Caspar F (2011). Internet-based treatment of depression: a randomized controlled trial comparing guided with unguided self-help. Cognitive Behaviour Therapy 40, 251-266.

Bergin AE (1966). Some implications of psychotherapy research for therapeutic practice. Journal of Abnormal Psychology 71, 235-246.

Berto P, D'Ilario D, Ruffo P, Di Virgilio R, Rizzo F (2000). Depression: cost-of-illness studies in the international literature, a review. Journal of Mental Health Policy and Economics 3, 3-10.

Boettcher J, Rozental A, Andersson G, Carlbring P (2014). Side effects in internet-based interventions for social anxiety disorder. Internet Interventions 1, 3-11.

Borenstein M, Hedges LV, Higgins JPT, Rothstein HR (2009). Introduction to Meta-Analysis. Wiley: Chichester, UK.

Brookes ST, Whitely E, Egger M, Smith GD, Mulheran PA, Peters TJ (2004). Subgroup analyses in randomized trials: risks of subgroup-specific analyses; power and sample size for the interaction test. Journal of Clinical Epidemiology 57, 229-236.

Carlbring P, Hägglund M, Luthström A, Dahlin M, Kadowaki Å, Vernmark K, Andersson G (2013). Internet-based behavioral activation and acceptance-based treatment for depression: a randomized controlled trial. Journal of Affective Disorders 148, 331-337.

Cavanagh K, Seccombe N, Lidbetter N (2011). The implementation of computerized cognitive behavioural therapies in a service user-led, third sector self-help clinic. Behavioural and Cognitive Psychotherapy 39, 427-442.
Choi I, Zou J, Titov N, Dear BF, Li S, Johnston L, Andrews G, Hunt C (2012). Culturally attuned Internet treatment for depression amongst Chinese Australians: a randomised controlled trial. Journal of Affective Disorders 136, 459-468.

Clarke MJ (2005). Individual patient data meta-analyses. Best Practice and Research. Clinical Obstetrics and Gynaecology 19, 47-55.

Cooper H, Patall EA (2009). The relative benefits of meta-analysis conducted with individual participant data versus aggregated data. Psychological Methods 14, 165-176.

Cuijpers P, Karyotaki E, Weitz E, Andersson G, Hollon SD, van Straten A (2014). The effects of psychotherapies for major depression in adults on remission, recovery and improvement: a meta-analysis. Journal of Affective Disorders 159, 118-126.

Cuijpers P, van Straten A, Andersson G, van Oppen P (2008a). Psychotherapy for depression in adults: a meta-analysis of comparative outcome studies. Journal of Consulting and Clinical Psychology 76, 909-922.

Cuijpers P, van Straten A, Warmerdam L, Andersson G (2008b). Psychological treatment of depression: a meta-analytic database of randomized studies. BMC Psychiatry 8, 36.

Curtin F, Schulz P (2011). Assessing the benefit: risk ratio of a drug-randomized and naturalistic evidence. Dialogues in Clinical Neuroscience 13, 183-190.

DerSimonian R, Laird N (1986). Meta-analysis in clinical trials. Controlled Clinical Trials 7, 177-188.

Dimidjian S, Hollon SD (2010). How would we know if psychotherapy were harmful? American Psychologist 1, 21-33.

Duval S, Tweedie R (2000). Trim and fill: a simple funnel-plot-based method of testing and adjusting for publication bias in meta-analysis. Biometrics 56, 455-463.

Ebert DD, Berking M, Heber E, Riper H, Laferton J, Cuijpers P, Lehr D (2015a). Restoring depleted resources: efficacy and mechanisms of change of an Internet-based unguided recovery training for better sleep and psychological detachment from work. Health Psychology 34 (Suppl.), 1240-1251.

Ebert DD, Lehr D, Baumeister H, Boß L, Riper H, Cuijpers P, Reins JA, Buntrock C, Berking M (2014a). GET.ON Mood Enhancer: efficacy of Internet-based guided self-help compared to psychoeducation for depression: an investigator-blinded randomised controlled trial. Trials $15,39$.

Ebert DD, Lehr D, Boß L, Riper H, Cuijpers P, Andersson G, Thiart H, Heber E, Berking M (2014c). Efficacy of an internet-based problem-solving training for teachers: results of a randomized controlled trial. Scandinavian Journal of Work, Environment and Health 40, 582-596.

Ebert DD, Zarski A-C, Christensen H, Stikkelbroek Y, Cuijpers P, Berking M, Riper H (2015b). Internet and computer-based cognitive behavioral therapy for anxiety and depression in youth: a meta-analysis of randomized controlled outcome trials. PLOS ONE 10, e0119895.

Egger M, Davey Smith G, Schneider M, Minder C (1997). Bias in meta-analysis detected by a simple, graphical test. British Medical Journal (Clinical Research Edition) 315, 629-634. 
Emmelkamp PMG, David D, Beckers T, Muris P, Cuijpers P, Lutz W, Andersson G, Araya R, Banos Rivera RM, Barkham M, Berking M, Berger T, Botella C, Carlbring P, Colom F, Essau C, Hermans D, Hofmann SG, Knappe S, Ollendick TH, Raes F, Rief W, Riper H, Van Der Oord S, Vervliet B (2014). Advancing psychotherapy and evidencebased psychological interventions. International Journal of Methods in Psychiatric Research 23 (Suppl. 1), 58-91.

Garfield SL, Prager RA, Bergin AE (1971). Evaluating outcome in psychotherapy: a hardy perennial. Journal of Consulting and Clinical Psychology 37, 320-322.

Greenberg PE, Birnbaum HG (2005). The economic burden of depression in the US: societal and patient perspectives. Expert Opinion on Pharmacotherapy 6, 369-376.

Hansen NB, Lambert MJ, Forman EM (2006). The psychotherapy dose-response effect and its implications for treatment delivery services. Clinical Psychology: Science and Practice 9, 329-343.

Hedman E, Ljótsson B, Lindefors N (2012). Cognitive behavior therapy via the Internet: a systematic review of applications, clinical efficacy and cost-effectiveness. Expert Review of Pharmacoeconomics and Outcomes Research 12, 745-764.

Higgins JPT, Altman DG, Sterne JAC (eds) (2011). Chapter 8: Assessing risk of bias in included studies. In: Cochrane Handbook for Systematic Reviews of Interventions, version 5.1.0 (updated March 2011), (updated March 2011) (ed. J. P. T. Higgins \& S. Green). The Cochrane Collaboration, 2011 (www.cochrane-handbook.org). The Atrium, Southern Gate, Chichester.

Ioannidis JPA, Patsopoulos NA, Evangelou E (2007). Uncertainty in heterogeneity estimates in meta-analyses. British Medical Journal (Clinical Research Edition) 335, 914-916.

Jacobson NS, Truax P (1991). Clinical significance: a statistical approach to denning meaningful change in psychotherapy research. Psychology 59, 12-19.

Johansson R, Andersson G (2012). Internet-based psychological treatments for depression. Expert Review of Neurotherapeutics 12, 861-869.

Johansson R, Ekbladh S, Hebert A, Lindström M, Möller S, Petitt E, Poysti S, Larsson MH, Rousseau A, Carlbring P, Cuijpers P, Andersson G (2012a). Psychodynamic guided self-help for adult depression through the internet: a randomised controlled trial. PLOS ONE 7, e38021.

Johansson R, Sjöberg E, Sjögren M, Johnsson E, Carlbring P, Andersson T, Rousseau A, Andersson G (2012b). Tailored vs. standardized internet-based cognitive behavior therapy for depression and comorbid symptoms: a randomized controlled trial. PLOS ONE 7, e36905.

Kessler RC, Chiu WT, Demler O, Merikangas KR, Walters EE (2005). Prevalence, severity, and comorbidity of 12-month DSM-IV disorders in the National Comorbidity Survey Replication. Archives of General Psychiatry 62, 617-627.

Kiluk BD, Sugarman DE, Nich C, Gibbons CJ, Martino S, Rounsaville BJ, Carroll KM (2011). A methodological analysis of randomized clinical trials of computer-assisted therapies for psychiatric disorders: toward improved standards for an emerging field. American Journal of Psychiatry 168, 790-799.

Kleiboer A, Donker T, Seekles W, van Straten A, Riper H, Cuijpers $\mathbf{P}$ (2015). A randomized controlled trial on the role of support in internet-based problem solving therapy for depression and anxiety. Behaviour Research and Therapy 72, 63-71.

Kohn R, Saxena S, Levav I, Saraceno B (2004). The treatment gap in mental health care. Bulletin of the World Health Organization 82, 858-866.

Ladwig I, Rief W, Nestoriuc Y (2014). Welche Risiken und Nebenwirkungen hat Psychotherapie? - Entwicklung des Inventars zur Erfassung Negativer Effekte von Psychotherapie (INEP). Verhaltenstherapie 24, 252-263.

Lambert MJ, Whipple JL, Hawkins EJ, Vermeersch DA, Nielsen SL, Smart DW (2006). Is it time for clinicians to routinely track patient outcome? A meta-analysis. Clinical Psychology: Science and Practice 10, 288-301.

Lilienfeld SO (2007). Psychological treatments that cause harm. Perspectives on Psychological Science 2, 53-70.

Linden M (2013). How to define, find and classify side effects in psychotherapy: from unwanted events to adverse treatment reactions. Clinical Psychology and Psychotherapy 20, 286-296.

Martinez R, Whitfield G, Dafters R, Williams C (2007). Can people read self-help manuals for depression? a challenge for the stepped care model and book prescription schemes. Behavioural and Cognitive Psychotherapy 36, 89-97.

Mohr DC (1995). Negative outcome in psychotherapy: a critical review. Clinical Psychology: Science and Practice 2, 1-27.

Newby JM, Mackenzie A, Williams AD, McIntyre K, Watts S, Wong N, Andrews G (2013). Internet cognitive behavioural therapy for mixed anxiety and depression: a randomized controlled trial and evidence of effectiveness in primary care. Psychological Medicine 43, 2635-2648.

Orsini N, Higgins J, Bottai M, Buchan I (2013). Heterogi: Stata module to quantify heterogeneity in a meta-analysis.

Perini S, Titov N, Andrews G (2009). Clinician-assisted Internet-based treatment is effective for depression: randomized controlled trial. Australian and New Zealand Journal of Psychiatry 43, 571-578.

Radloff LS (1977). The CES-D scale: a self-report depression scale for research in the general population. Applied Psychological Measurement 1, 385-401.

Richards D, Richardson T (2012). Computer-based psychological treatments for depression: a systematic review and meta-analysis. Clinical Psychology Review 32, 329-342.

Riley RD, Lambert PC, Abo-Zaid G (2010). Meta-analysis of individual participant data: rationale, conduct, and reporting. British Medical Journal (Clinical Research Edition) 340, c221.

Rozental A, Andersson G, Boettcher J, Ebert DD, Cuijpers P, Knaevelsrud C, Ljótsson B, Kaldo V, Titov N, Carlbring P (2014). Consensus statement on defining and measuring negative effects of Internet interventions. Internet Interventions 1, 12-19.

Rozental A, Boettcher J, Andersson G, Schmidt B, Carlbring P (2015). Negative effects of internet interventions: a 
qualitative content analysis of patients' experiences with treatments delivered online. Cognitive Behaviour Therapy 44, 223-236.

Ruwaard J, Schrieken B, Schrijver M, Broeksteeg J, Dekker J, Vermeulen H, Lange A (2009). Standardized web-based cognitive behavioural therapy of mild to moderate depression: a randomized controlled trial with a long-term follow-up. Cognitive Behaviour Therapy 38, 206-221.

Saarni SI, Suvisaari J, Sintonen H, Pirkola S, Koskinen S, Aromaa A, Lönnqvist J (2007). Impact of psychiatric disorders on health-related quality of life: general population survey. British Journal of Psychiatry 190, 326-332.

Schafer JL, Graham JW (2002). Missing data : our view of the state of the art. Psychological Methods 7, 147-177.

Sheeber LB, Seeley JR, Feil EG, Davis B, Sorensen E, Kosty DB, Lewinsohn PM (2012). Development and pilot evaluation of an Internet-facilitated cognitive-behavioral intervention for maternal depression. Journal of Consulting and Clinical Psychology 80, 739-749.

Smit F, Cuijpers P, Oostenbrink J, Batelaan N, de Graaf R, Beekman A (2006). Costs of nine common mental disorders: implications for curative and preventive psychiatry. Journal of Mental Health Policy and Economics 9, 193-200.

Smith ML, Glass GV (1977). Meta-analysis of psychotherapy outcome studies. American Psychologist 32, 752-760.

Spek V, Nyklícek I, Cuijpers P, Pop V (2008). Predictors of outcome of group and internet-based cognitive behavior therapy. Journal of Affective Disorders 105, 137-145.

Strupp HH, Hadley SW, Gomes-Schwartz B (1977). Psychotherapy for Better or Worse: the Problem of Negative Effects. Jason Aronson Inc. Publishers. New York.

Titov N, Andrews G, Davies M, McIntyre K, Robinson E, Solley K (2010). Internet treatment for depression: a randomized controlled trial comparing clinician vs. technician assistance. PLoS ONE 5, e10939.

Titov N, Dear BF, Schwencke G, Andrews G, Johnston L, Craske MG, McEvoy P (2011). Transdiagnostic internet treatment for anxiety and depression: a randomised controlled trial. Behaviour Research and Therapy 49, 441-452.

Ünlü Ince B, Cuijpers P, van 't Hof E, van Ballegooijen W, Christensen H, Riper H (2013). Internet-based, culturally sensitive, problem-solving therapy for Turkish migrants with depression: randomized controlled trial. Journal of Medical Internet Research 15, e227.

Ustün TB, Ayuso-Mateos JL, Chatterji S, Mathers C, Murray CJL (2004). Global burden of depressive disorders in the year 2000. British Journal of Psychiatry: the Journal of Mental Science 184, 386-392.

van Bastelaar KMP, Pouwer F, Cuijpers P, Riper H, Snoek FJ (2011). Web-based depression treatment for type 1 and type 2 diabetic patients: a randomized, controlled trial. Diabetes Care 34, 320-325.

van Straten A, Cuijpers P, Smits N (2008). Effectiveness of a web-based self-help intervention for symptoms of depression, anxiety, and stress: randomized controlled trial. Journal of Medical Internet Research 10, e7.

Vernmark K, Lenndin J, Bjärehed J, Carlsson M, Karlsson J, Oberg J, Carlbring P, Eriksson T, Andersson G (2010). Internet administered guided self-help versus individualized e-mail therapy: a randomized trial of two versions of CBT for major depression. Behaviour Research and Therapy 48, 368-376.

Waraich P, Goldner EM, Somers JM, Hsu L (2004). Prevalence and incidence studies of mood disorders: a systematic review of the literature. Canadian Journal of Psychiatry 49, 124-138.

Warmerdam L, Van Straten A, Twisk J, Cuijpers P (2013). Predicting outcome of Internet-based treatment for depressive symptoms. Psychotherapy Research: Journal of the Society for Psychotherapy Research 23, 559-567.

Warmerdam L, van Straten A, Twisk J, Riper H, Cuijpers $\mathbf{P}$ (2008). Internet-based treatment for adults with depressive symptoms: randomized controlled trial. Journal of Medical Internet Research 10, e44.

Willan AR, O'Brien BJ, Cook DJ (1997). Benefit-risk ratios in the assessment of the clinical evidence of a new therapy. Controlled Clinical Trials 18, 121-130.

Wittchen H-U, Jacobi F, Rehm J, Gustavsson A, Svensson M, Jönsson B, Olesen J, Allgulander C, Alonso J, Faravelli C, Fratiglioni L, Jennum P, Lieb R, Maercker A, van Os J, Preisig M, Salvador-Carulla L, Simon R, Steinhausen H-C (2011). The size and burden of mental disorders and other disorders of the brain in Europe 2010. European Neuropsychopharmacology 21, 655-679. 